\title{
Homocystinuria Due to Cystathionine Synthase Deficiency: The Metabolism of L-Methionine*
}

\author{
Leonard Laster, $†$ S. Harvey Mudd, James D. Finkelstein, and Filadelfo \\ IRREVERRE WITH THE TECHNICAL ASSISTANCE OF BRINSON CONERLY \\ (From the National Institute of Arthritis and Metabolic Diseases and the National Institute of \\ Mental Health, National Institutes of Health, Bethesda, Md.)
}

During surveys of mentally retarded patients for evidence of metabolic errors, investigators in Ireland (1) and in America (2) independently discovered that abnormal excretion of homocystine in the urine may accompany retardation. A syndrome has since been defined (3-9) with the relatively constant clinical features of mental deficiency, fine, fair hair, dislocated ocular lenses, malar flush, peculiar gait, and genu valgum; and with the variable features of pes cavus, long extremities and digits, convulsions, thrombotic incidents that have been attributed to abnormal stickiness of the platelets (10), cardiovascular disorders, and fatty liver. Almost without exception the patients have had elevated concentrations of methionine and homocystine in the blood plasma in addition to increased amounts of homocystine in the urine.

A mentally retarded child, C.T., with many of the clinical and all of the biochemical abnormalities of the disorder, has been shown to lack detectable activity of cystathionine synthase ${ }^{1}$ in her liver (12). This enzyme catalyzes a reaction involved in methionine metabolism (reaction 4, Figure 1), and we have proposed that deficiency of cystathionine synthase activity is the fundamental defect in the disease. The parents of C.T., who are free of clinical stigmata of the disease and who do not excrete abnormal amounts of homocystine in the urine,

* Submitted for publication May 5, 1965 ; accepted July 6, 1965 .

† Address requests for reprints to Dr. Leonard Laster, Gastroenterology Unit, National Institute of Arthritis and Metabolic Diseases, Bethesda, Md. 20014.

1 Although we have referred to this enzyme as "cystathionine synthetase" in earlier publications, we are now using the designation "cystathionine synthase" to conform to the presently recommended nomenclature (11). Cystathionine synthase is the trivial name for the enzyme L-serine hydro-lyase (adding L-homocysteine), E.C.4.2.1.21. have approximately half the mean control hepatic cystathionine synthase activity and thus appear to be heterozygous for the abnormal gene (13). A paternal cousin of C.T. excretes abnormal amounts of homocystine in the urine, but is neither mentally retarded nor otherwise afflicted with clinical manifestations of the syndrome. Her hepatic cystathionine synthase activity is between that of the heterozygous parents and that of C.T. (13). Although her genetic status is not clear, the cousin demonstrates that cystathionine synthase deficiency severe enough to cause homocystinuria does not necessarily cause mental retardation.

The concentration of cystathionine in brain tissue from patients with the typical clinical features of cystathionine synthase deficiency has been shown to be markedly lower than in brain tissue from control subjects $(14,15)$. This abnormality is consistent with the concept that cystathionine synthase deficiency is the fundamental defect, since current knowledge suggests that the body's endogenous cystathionine derives exclusively from the reaction catalyzed by the synthase.

In the present study some of the metabolic consequences of cystathionine synthase deficiency were explored. Feeding methionine to normal human subjects increases urinary excretion of inorganic sulfate $(16,17)$. There is abundant evidence showing that the pathway represented by reactions 1 to 6 in Figure 1 is a possible route in mammals for the conversion of the sulfur of methionine to inorganic sulfate (reviewed in references 18 and 19). However, the evidence that this pathway is the predominant one is far less convincing. It was possible to test whether reaction 4 is an obligatory step in the pathway by feeding L-methionine and L-cysteine to control subjects and to patients with cystathionine synthase deficiency and determining their subsequent urinary excretion of inorganic 


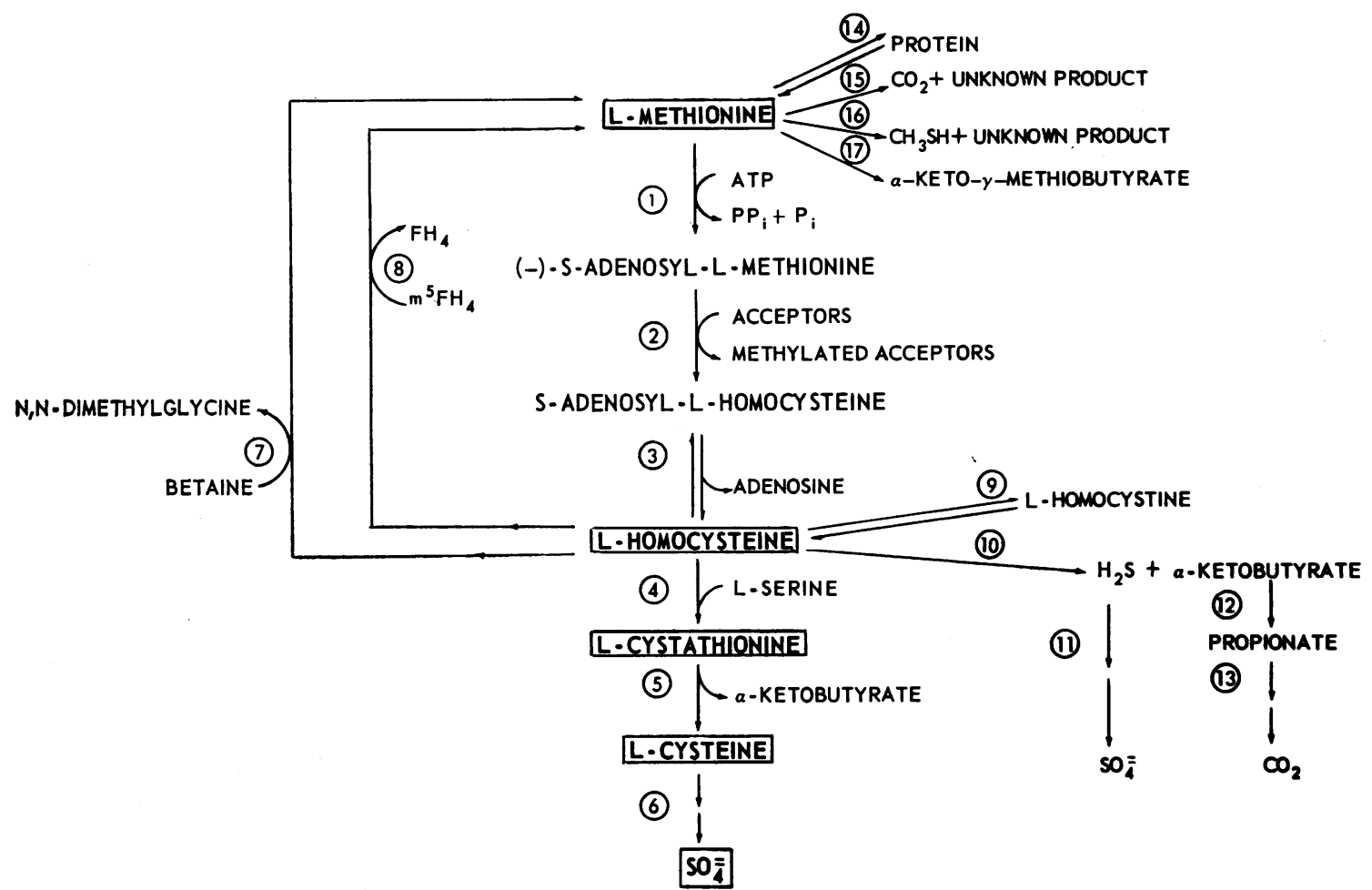

Fig. 1. Current concepts of methionine metabolism in mammalian tissues. $P_{1}$ and $P_{P_{1}}$ are inorganic phosphate and pyrophosphate. $\mathrm{FH}_{4}$ is tetrahydrofolic acid and $\mathrm{m}^{5} \mathrm{FH}_{4}$ is $\mathrm{N}^{5}$-methyltetrahydrofolic acid.

sulfate. A patient with cystathionine synthase deficiency would be unable, or limited in his capacity, to convert the sulfur atom of L-methionine, but not of L-cysteine, to inorganic sulfate if the following conditions were met: $a$ ) reaction 4 must indeed be a step in the major human pathway for methionine metabolism to inorganic sulfate; $b$ ) the pathway beyond reaction 4 must be intact in patients with cystathionine synthase deficiency; and $c$ ) the finding of cystathionine synthase deficiency in the liver must reflect a generalized reduction in the body's ability to convert homocysteine to cystathionine. The results suggest that all three conditions are met.

\section{Methods}

Clinical. The control subjects appeared to be in good health and were evaluated by a medical history, physical examination, and laboratory tests. They included five normal volunteers and S.M., the maternal grandmother of C.T., whose hepatic cystathionine synthase activity has been shown to be within the range of control values (13). Urine from each control subject gave a negative reaction with the cyanide-nitroprusside test $(20)$, which has been used to screen for homocystinuria $(4,6)$.

The patients with cystathionine synthase deficiency, C.T. and M.A.G., have been briefly described elsewhere $(12,13)$, and detailed case reports will be published (21).

The subjects received constant diets low in methionine and cystine. Food was prepared and served under the supervision of a dietician trained in techniques of metabolic balance studies. Values for daily intake of methionine and cystine in the diet were calculated from published tables (22). Each subject's body weight remained essentially unchanged during a study.

L-Methionine ${ }^{2}$ and L-cysteine ${ }^{2}$ were made up in gelatin capsules, each containing $0.25 \mathrm{~g}$ of amino acid. When an amino acid was fed repeatedly for several days, the total daily intake was divided into four doses. When a single dose was given, the subject was fasted from 10 p.m. the previous night, the amino acid was administered at 8 a.m., and breakfast was fed at 9 a.m.

Urine specimens were refrigerated immediately after they were passed and were preserved with toluene. The specimens were pooled and frozen at the end of a collection period (duration, 24 hours or fractions thereof).

Analytical. Blood drawn for amino acid analysis was added to heparin, its plasma was deproteinized with picric

\footnotetext{
2 Mann Research Laboratories, New York, N. Y.
} 
acid (23), and the supernatant solution was stored frozen. Amino acids of blood plasma and urine were determined with an automatic amino acid analyzer according to Spackman, Stein, and Moore (24). Urinary content of total sulfur, inorganic and ethereal sulfates, and neutral sulfur was determined according to Fiske's modification of the method of Rosenheim and Drummond (25).

\section{Results}

Prolonged feeding of L-methionine or L-cysteine. The results of a typical study of a control subject are shown in Figure 2. The dietary intake of methionine and cystine was constant during the 27 -day study. The first 3 days were control days; during days 4 to 6 , when the subject received supplementary L-cysteine, his urinary excretion of inorganic sulfate rose promptly and remained elevated throughout this period. During days 10 to 12 he received supplementary L-methionine, and his urinary excretion of inorganic sulfate rose and fell as it had done during L-cysteine supplementation. On the mornings of days 17 and 19 he was given single doses (see arrows in Figure 2) of L-cysteine and L-methionine, respectively. These studies of acute loading are described in the next section. During days 23 to 25 he received supplementary L-methionine again, but in a higher dose. The resulting increase in urinary excretion of inorganic sulfate was greater than it had been during days 10 to 12 . Similar results were obtained during studies of three other normal volunteers and of S.M., the grandmother of C.T.

The responses of the two patients with cystathionine synthase deficiency differed strikingly from those of the control subjects in that there was a much smaller rise in urinary excretion of inorganic sulfate during supplementation with L-methi-

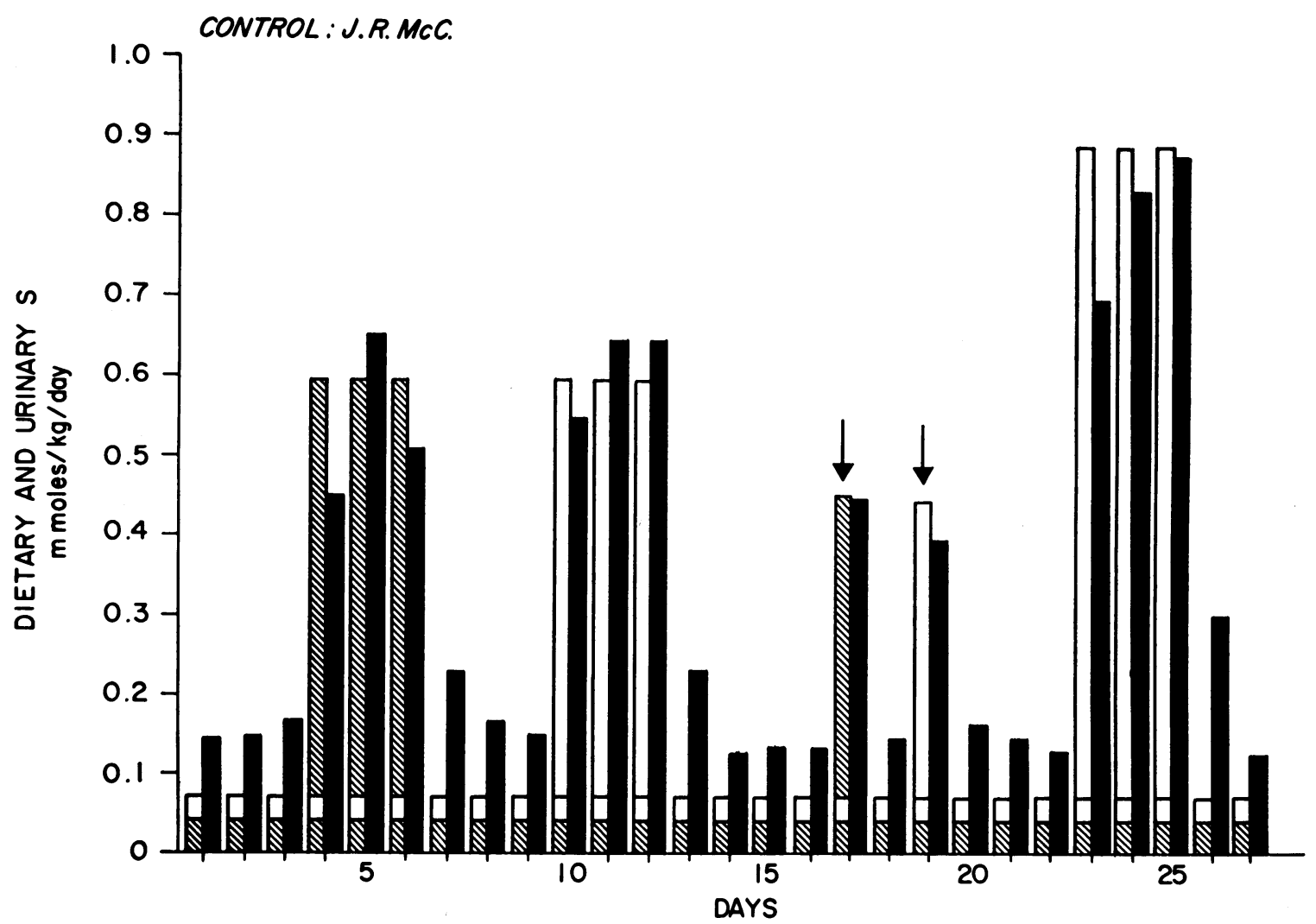

Fig. 2. URINARY EXCRETION OF INORGaNiC SUlFATE AFTER THE ADMINISTRATION OF L-METHIONINE OR L-CYSTEINE to A CONTROL SUBJECT. Each day is represented by two bars. The right-hand bar represents urinary inorganic sulfate. The left-hand bar represents intake of methionine (open rectangles) plus cyst(e) ine (hatched rectangles). The subdivisions of the left-hand bar represent dietary intake (the two lower rectangles) and supplementary dose (the third and highest rectangle). The arrows indicate single doses of the amino acids. During the periods of prolonged supplementation the daily dose of amino acid was divided into four parts. 


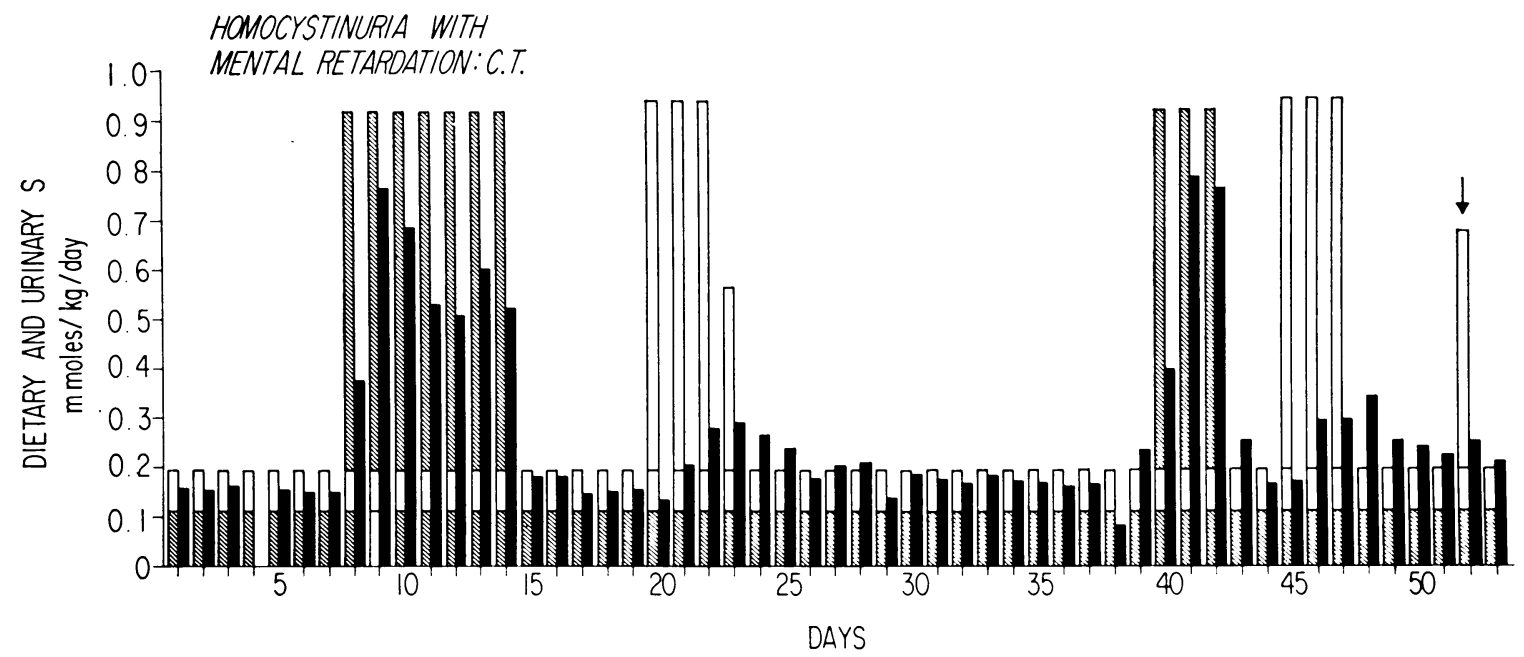

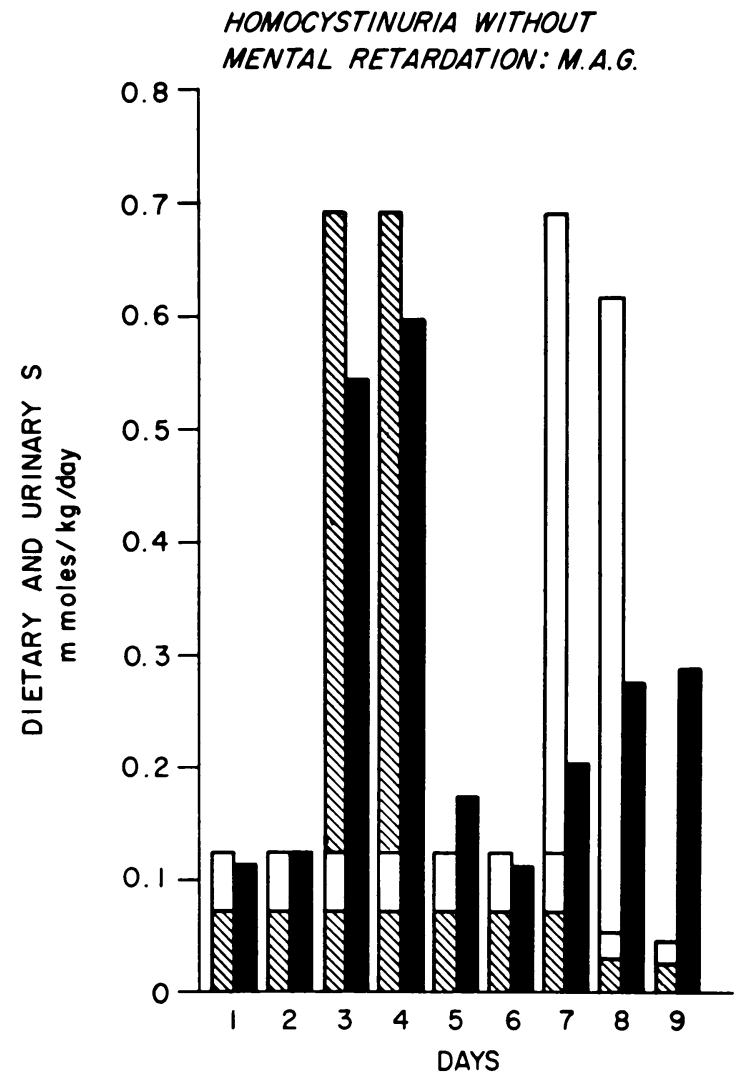

Fig. 3 aNd 4. URINARY EXCRETION OF INORGANIC SLLFATE AFTER THE ADMINISTRATION OF L-METHIONINE OR L-CYSTEINE TO PATIENTS WITH CYSTATHIONINE SYNTHASE Deficiexicy. The charts are explained in the legend to Figure 2. The following changes in the protocol had to be made: since C.T. developed anorexia on day 23 , her dose of L-methionine was halved; M.A.G. developed anorexia and nausea and decreased her dietary intake of methionine on days 7 and 8 . onine (Figure 3, days 20 to 23 and 45 to 47 , and Figure 4, days 7 and 8).

The relationship between the total intake of methionine and the urinary excretion of inorganic sulfate was analyzed by administration of a range of closes of supplementary L-methionine to the control subjects (Figure 5 ). This range bracketed the doses given to the two patients with cystathionine synthase deficiency. The total intake of methionine was calculated by adding the values for dietary methionine and supplementary L-methionine. The observed values for urinary inorganic sulfate were converted to values for urinary inorganic sulfate attributable to methionine intake by making a small correction for estimated urinary inorganic sulfate attributable to cyst(e) ine intake. First, it was assumed that during the control periods the total urinary inorganic sulfate was made up of inorganic sulfate attributable to dietary cystine and to dietary methionine in proportion to the dietary intake of each amino acid. On the basis of this assumption a value was calculated for urinary sulfate attributable to dietary cystine intake during the control periods. This value was subtracted from the value for total urinary inorganic sulfate during the first and second days of L-methionine supplementation. The correction was small and did not change the qualitative considerations.

The urinary excretion of inorganic sulfate by the control subjects increased in relationship to methionine intake, an increment in dose producing an approximately equivalent increment in excretion of inorganic sulfate. The values for the two 
patients are below the curves established for the control subjects, regardless of whether the data are expressed in terms of body weight, as shown in Figure 5, or in terms of body surface area, and regardless of whether the first or second day of L-methionine supplementation is considered. Thus, each patient with cystathionine synthase deficiency fails to excrete as much inorganic sulfate in response to an increase in methionine intake as do control subjects, and appears, therefore, to have a reduced capacity to catabolize L-methionine to inorganic sulfate.
In contrast, the responses of the two patients with cystathionine synthase deficiency to the supplementary administration of L-cysteine did not differ significantly from those of the control subjects (Figures 2 to 4 ). In both the patients and the control subjects there was a rapid and significant increase in urinary excretion of inorganic sulfate after an increase in intake of L-cysteine. A graphic analysis of the dose-response relationship for L-cysteine, analogous to the one described for L-methionine, is presented in Figure 6 . The values for urinary excretion of inorganic sulfate

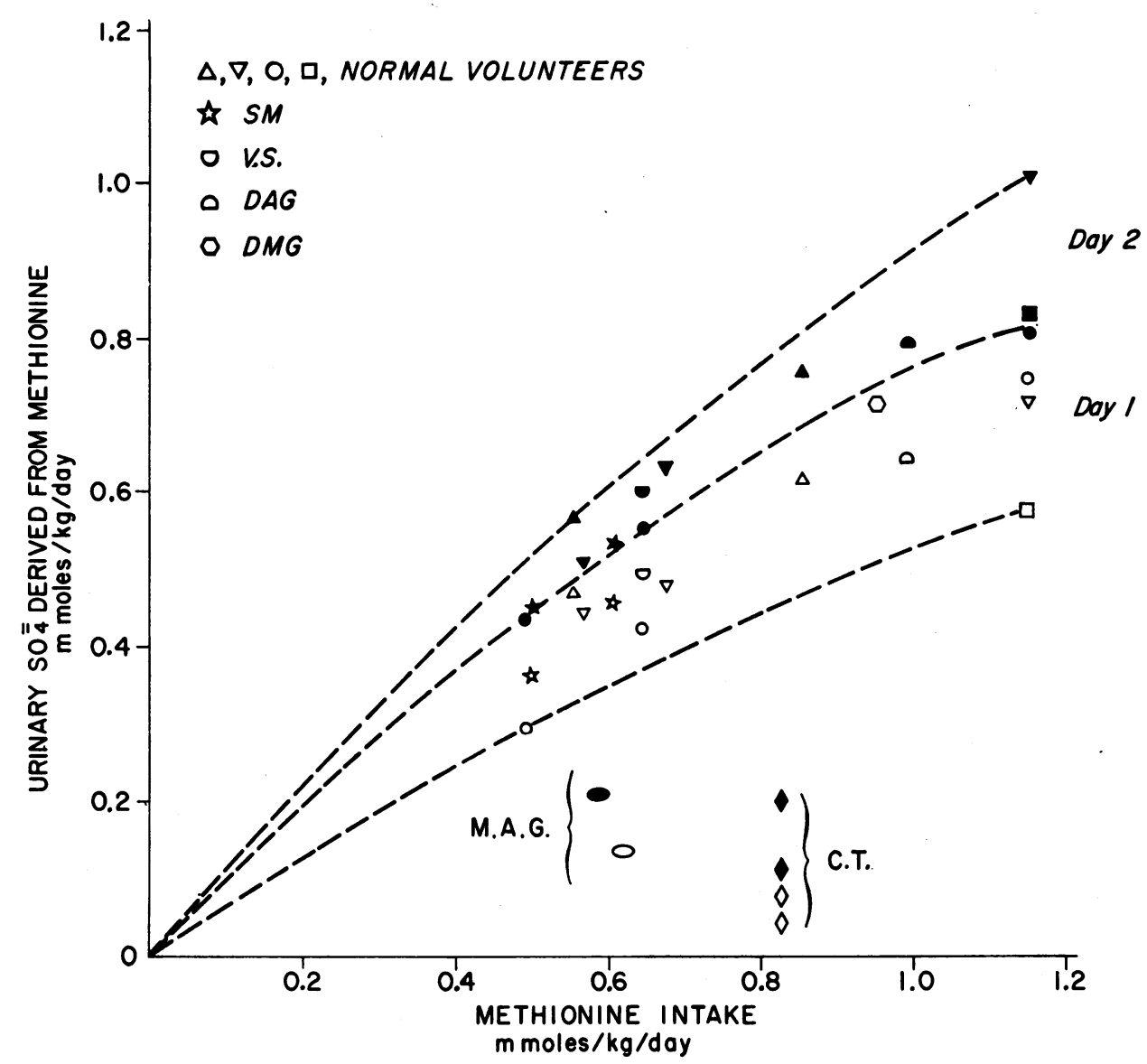

Fig. 5. DOSE-RESPONSE RELATIONSHIP BETWEEN METHIONINE INTAKE AND URINARY EXCRETION OF INORGANIC SULFATE. The data are from the studies in which supplementary L-methionine was given repeatedly for several days. Responses are presented for the first and second days of supplementation. Open symbols represent day 1 ; black symbols represent day 2 . The dotted lines show the limits of the control range. The homocystinuric patients are indicated by their initials on the Figure.

The subjects included, in addition to the normal volunteers, S.M., the grandmother of C.T.; V.S., a 33-year-old maternal aunt of C.T. who has no clinical evidence of cystathionine synthase deficiency; and D.A.G. and D.M.G., two children of M.A.G. who are both free of clinical evidence of the disorder. 


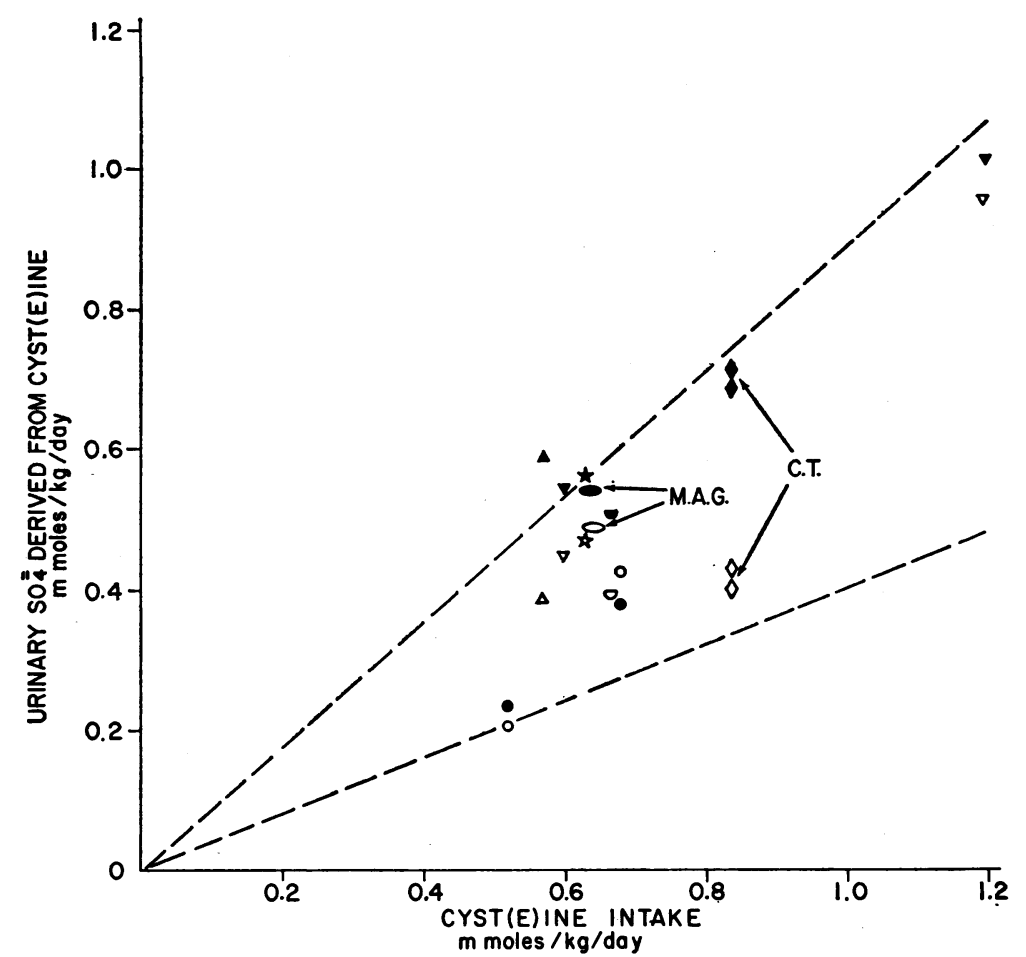

Fig. 6. Dose-Response Relationship BETWEen CYST(E)INE INTAKE AND URINARY EXCRETION OF INORGANIC SULFATE. The symbols in this Figure are identical to those in Figure 5.

by C.T. and M.A.G. during both the first and second days of L-cysteine supplementation are within the control range. Thus, under the conditions of this study the ability of each of these patients to increase urinary excretion of inorganic sulfate in response to a dose of L-cysteine is not impaired.

One possible explanation for the reduced capacity of the patients with cystathionine synthase deficiency to increase urinary excretion of inorganic sulfate after an increase in the dose of $\mathrm{L}$-methionine is that their intestinal absorption of L-methionine is impaired. To explore this possibility we determined the concentration of methionine and its sulfoxide in the plasma of C.T. before and after a period during which she received supplementary L-methionine. On day 14 (Figure 3) there were $8 \mu$ moles per $100 \mathrm{ml}$ of methionine in her plasma and only a trace of methionine sulfoxide, whereas on day 23 , after she had received supplementary L-methionine for 3 days, the concentration of methionine in her plasma had increased to $135 \mu$ moles per $100 \mathrm{ml}$, and there was $57 \mu$ moles of methionine sulfoxide per $100 \mathrm{ml}$. Comparable values for a study of a control subject were methionine, 2 , and methionine sulfoxide, $0, \mu$ moles per 100 $\mathrm{ml}$ of plasma before the administration of $\mathrm{L}$-methionine; and methionine, 2 , and methionine sulfoxide, trace, $\mu$ moles per $100 \mathrm{ml}$ of plasma after 4 days of L-methionine supplementation. These findings show that the L-methionine had been absorbed by C.T. and had accumulated in her body fluids.

The two patients with cystathionine synthase deficiency differed from the control subjects not only in the magnitude of their responses to an increase in the intake of L-methionine, but also in the pattern of their responses to the omission of the supplementary L-methionine. On each of the days that the L-methionine supplement was first discontinued, the control subjects excreted less inorganic sulfate in the urine than they had excreted during the last day of feeding the supplementary L-methionine, whereas C.T. (days 45 to 47, Figure 3) and M.A.G. (days 7 and 8, Figure 4) excreted more inorganic sulfate in the urine during 
the first day of L-methionine omission. These observations suggest that there was a delayed, but depressed, response to the administration of supplementary L-methionine in the patients with cystathionine synthase deficiency.

Response to a single dose of L-methionine or L-cysteine. Although assays of liver biopsy specimens have indicated that E.T. and L.T., the parents of C.T., are heterozygous for cystathionine synthase deficiency (13), they neither excrete abnormal amounts of homocystine in the urine, nor present clinical features of the syndrome associated with this deficiency. The response to a single dose of L-methionine was studied to learn whether it would provide a practical clinical means of detecting heterozygous subjects such as the parents.

The impaired ability of the homozygous patient, C.T., to metabolize L-methionine to inorganic sulfate is reflected not only in her response to the chronic administration of L-methionine, described above, but also in her response to a single dose of L-methionine (day 52, Figure 3). Her urinary excretion of inorganic sulfate on the date she received the single dose rose only slightly and to a much lesser extent than that of the control subjects. Figure 7 is a graph of the relationship between size of the single dose of L-methionine and the increment in 24-hour excretion of urinary inorganic sulfate. The value for C.T. is far below the control range.

Despite their partial reductions in hepatic cystathionine synthase activity, E.T. and L.T. responded to single doses of L-methionine in the same manner as the control subjects (Figure 7). The results of repeat tests of the parents were almost identical, and studies at two dosage levels failed to differentiate them from control subjects. The possibility was explored that measurement of the urinary excretion of inorganic sulfate during the early time periods after ingestion of L-methionine ( 0 to 5,5 to 8,8 to 16 , and 16 to 24 hours) might prove to be a more sensitive test of a metabolic difference between the heterozygous parents and the control subjects, but once again the results for the two groups were indistinguishable.

During studies of three control subjects and of E.T. and L.T. the rate of excretion of inorganic sulfate after a single dose of L-cysteine consistently reached a maximal value at an earlier time than

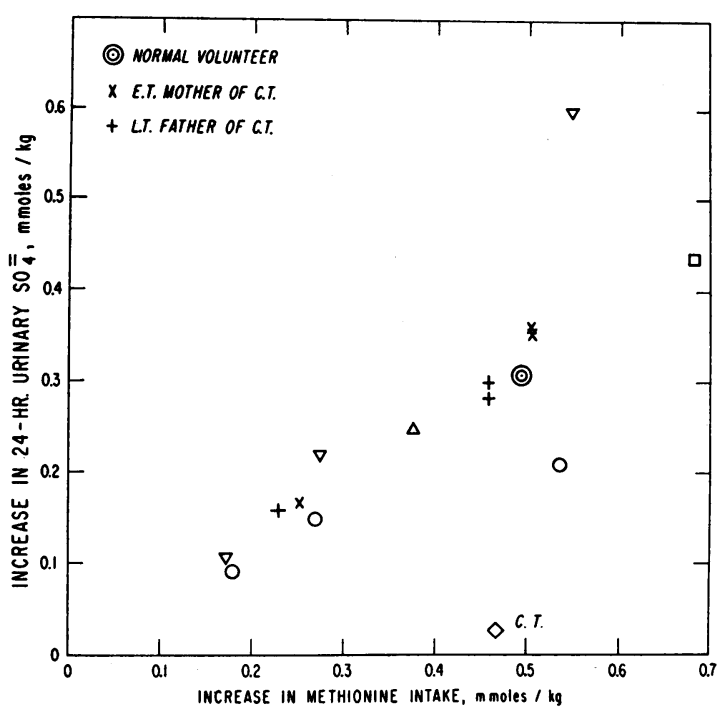

Fig. 7. EfFEct of A SINGLe dose of L-MEthionine on URINARY EXCRETION OF INORGANIC SULFATE DURING THE SUBSEQUENT 24 HOURS. The increment in methionine intake was the single dose of L-methionine. The increment in urinary excretion of inorganic sulfate was the difference between the excretion during the day of methionine administration and the immediately preceding day when no supplementary L-methionine had been given. Symbols not defined in this Figure are identical to those in Figure 5.

it did after a single dose of L-methionine (Figure $8)$. This observation is compatible with the possibility that one of the reactions between methionine and cysteine (Figure 1) is rate limiting for the over-all pathway from methionine to inorganic sulfate. That the delayed conversion of L-methionine to urinary inorganic sulfate is not attributable to delayed intestinal absorption of the amino acid is suggested by the finding that when a normal volunteer was fed the same dose of L-methionine that was used in the studies referred to in Figure 8 , the plasma concentration of methionine reached a peak value between $\frac{1}{2}$ and 1 hour. The values at $0, \frac{1}{2}, 1,2,3,4$, and 5 hours after ingestion of the methionine were $3.5,45.6,69.6,64.8,52.8$, 48.0 , and $39.6 \mu$ moles of methionine per $100 \mathrm{ml}$ of plasma.

The chemical forms in which C.T. excretes sulfur in her urine during periods of L-methionine administration. The preceding evidence indicating that a patient with cystathionine synthase deficiency converts much less of his dietary methionine to inorganic sulfate than a control subject 
does is in keeping with the formulation that the fundamental defect underlying homocystinuria is a block at reaction 4 (Figure 1). One might expect, too, that a patient with this inborn error would excrete a rather large fraction of the sulfur of his dietary methionine as homocystine. This is not the case. When C.T eats an average diet, with a daily methionine content of approximately 7 to 14 mmoles, she usually excretes an amount of homocystine in her urine that is equivalent to only about 0.4 to 0.5 mmole of sulfur. Because of this discrepancy we studied the fate of the remaining

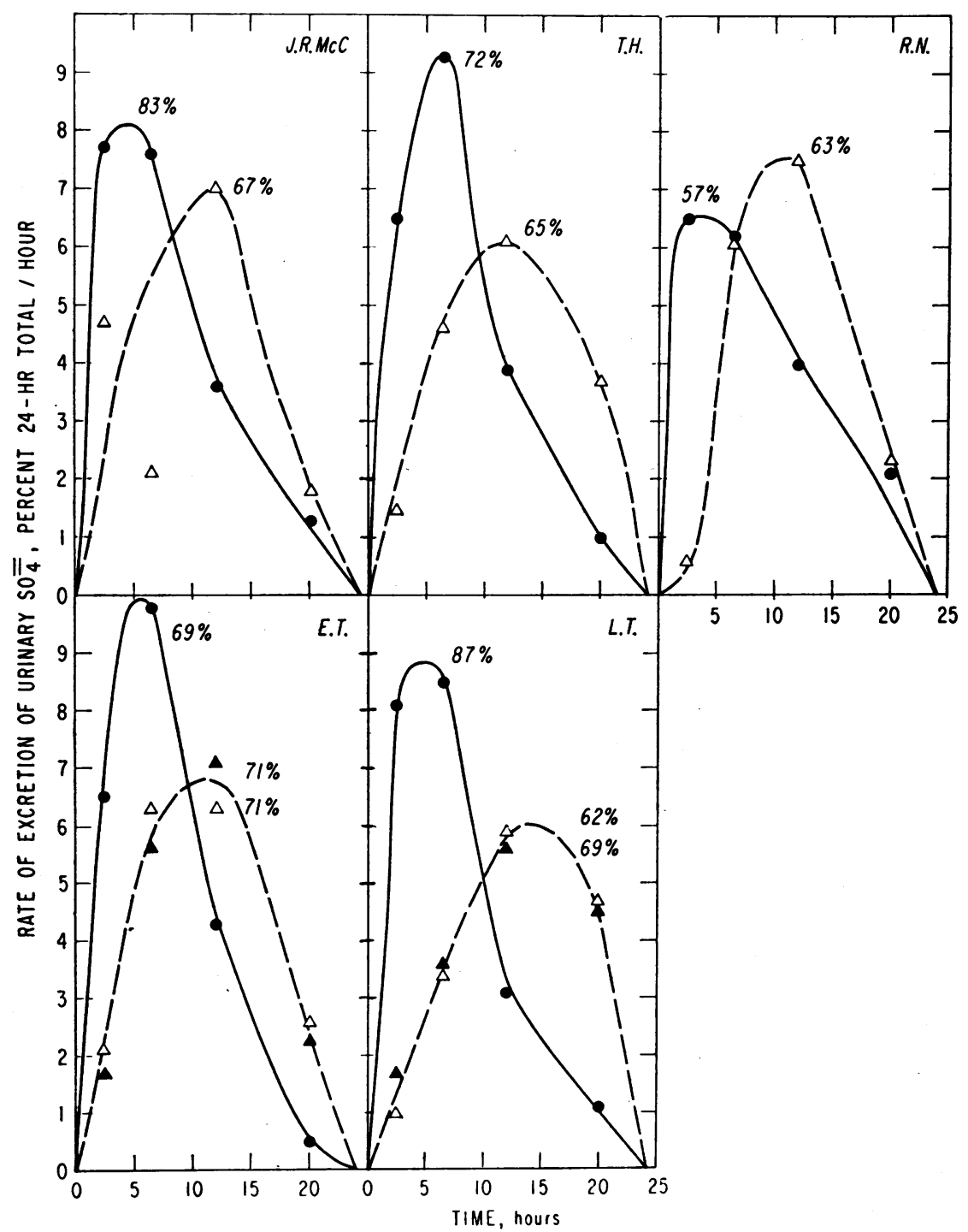

Fig. 8. RATE OF URINARY EXCRETION OF INORGANIC SULFATE AFTER ORAL ADMINISTRATION OF A SINGLE DOSE OF L-METHIONINE OR L-CYSTEINE TO THREE CONTROL SUBJECTS AND TO THE PARENTS OF C.T. In each study the dose of L-cysteine equaled that of L-methionine; the values were : J.R.McC., 0.4; T.H., 0.7 ; and R.N., E.T., and L.T., 0.5 mmole per $\mathrm{kg}$. The periods of the urine collections after the dose of an amino acid were 0 to 5,5 to 8,8 to 16 , and 16 to 24 hours. The values given in the Figure as per cent represent the per cent of the single dose of amino acid that was excreted as excess inorganic sulfate during the 24 hours after ingestion of the amino acid. The results of repeat studies of the effects of $\mathrm{L}$-methionine administration to E.T. and L.T. are presented.

0 , L-cysteine; $\Delta----\Delta$ and $\Delta----\Delta$, L-methionine. 
TABLE I

Sulfur-containing compounds in the urine after L-methionine administration

\begin{tabular}{|c|c|c|c|c|c|c|c|}
\hline \multirow[b]{3}{*}{ Subject } & \multirow{3}{*}{$\begin{array}{l}\text { Study } \\
\text { day }\end{array}$} & \multirow{3}{*}{$\begin{array}{l}\text { Supple- } \\
\text { mentary } \\
\text { L-methi- } \\
\text { onine }\end{array}$} & \multicolumn{4}{|c|}{ Chemical forms of urinary sulfur } & \multirow{3}{*}{$\begin{array}{l}\text { Bound } \\
\text { methi- } \\
\text { oninef }\end{array}$} \\
\hline & & & \multicolumn{2}{|c|}{ Sulfate } & \multicolumn{2}{|c|}{ Neutral sulfur } & \\
\hline & & & Inorganic & Ethereal & Amino acid* & Unidentified $\dagger$ & \\
\hline \multirow{7}{*}{ C.T, } & & mmoles/day & $\underset{\text { day }}{\text { mmoles/ }}$ & mmoles/day & $\underset{\text { day }}{\text { mmoles/ }}$ & mmoles/day & $\underset{\text { day }}{\text { mmoles/ }}$ \\
\hline & 15 & None & 5.7 & 0.3 & 1.32 & 1.2 & \\
\hline & 16 & None & 5.7 & 0.3 & 1.16 & 2.0 & \\
\hline & 19 & None & 4.9 & 0.5 & 1.47 & 0.2 & 0.25 \\
\hline & 21 & 23.5 & 6.4 & 0.8 & 0.51 & 4.2 & \\
\hline & 22 & 23.5 & 9.5 & 0.8 & 0.63 & 3.0 & 0.61 \\
\hline & 23 & 11.7 & 9.2 & 1.0 & 1.21 & 4.0 & 0.86 \\
\hline \multirow{5}{*}{ T.H. } & 7 & None & 11.3 & 1.0 & 0.53 & 1.3 & \\
\hline & 8 & None & 6.0 & 0.5 & 0.62 & 2.8 & 0.13 \\
\hline & 9 & 53.6 & 32.1 & 1.9 & 0.60 & Negative value & \\
\hline & 10 & 53.6 & 44.1 & 0.5 & 0.86 & 0.43 & \\
\hline & 11 & 53.6 & 45.1 & 2.2 & 0.94 & 0.33 & 0.27 \\
\hline \multirow{3}{*}{ J.R.McC. } & 9 & None & 13.3 & 0.2 & 0.67 & Negative value & 0.18 \\
\hline & 11 & 46.9 & 58.1 & Negative value & 0.89 & Negative value & \\
\hline & 12 & 46.9 & 58.1 & Negative value & 0.69 & Negative value & 0.16 \\
\hline
\end{tabular}

* The value for sulfur as urinary amino acids was calculated from the peaks observed in column chromatograms, which were regarded as corresponding to cysteic acid, taurine, methionine sulfoxide, cystine, cystathionine, methionine, mixed disulfide of homocysteine and cysteine, and glutathione.

$\dagger$ The value for neutral sulfur in unidentified chemical form was obtained by subtracting the value for sulfur in the form of amino acids (see previous footnote) from the value for the total amount of neutral sulfur in the urine.

$\ddagger$ Bound methionine represents methionine liberated by acid hydrolysis.

methionine to learn whether C.T. excretes in her urine metabolites of methionine or of homocysteine that are usually absent from or present only in trace amounts in the urine of control subjects.

The sulfur-containing compounds in urine that we identified by ion exchange column chromatography are listed in a footnote to Table I. The excretion of these compounds was measured for selected days from the studies of C.T. and the control subjects, T.H. and J.R.McC. Administration of supplementary L-methionine to C.T. in the doses shown did not significantly increase her urinary excretion of homocystine or of the mixed disulfide of homocysteine and cysteine. Others have also noted that no more than a small fraction of a load of homocystine or methionine is excreted as homocystine by homocystinuric subjects $(4,6$, 9 ), but the explanation of this finding is not apparent. During L-methionine administration C.T. excreted an average of only 0.1 mmole of homocystine daily. After oral administration of Lmethionine, C.T. and the two control subjects increased their urinary excretion of methionine and of methionine sulfoxide to approximately the same extent. Methionine excretion rose from about 0.02 to an average of about 0.20 mmole per day, and methionine sulfoxide excretion rose from undetectable levels to an average of about 0.25 mmole per day. Thus, the amount of these two compounds excreted fails to balance the discrepancy between the intake of methionine sulfur and the amount of urinary sulfate in C.T.

The urinary excretion of excess methionine by the control subjects stopped within about 2 days of discontinuation of L-methionine supplementation, but C.T. continued to excrete increased amounts of methionine and its sulfoxide in her urine for about 10 days after L-methionine supplementation was stopped on day 24 (Figure 3 ).

When the amounts of inorganic and ethereal sulfates are subtracted from the total sulfur of the urine, the difference is termed neutral sulfur. This value includes sulfur as the compounds identified with the amino acid analyzer and remaining sulfur in unidentified form. The latter is designated unidentified neutral sulfur. The value for neutral sulfur is obtained by subtraction of one large number from another, and the precision of the determinations is such that at times negative, meaningless values may be obtained. Despite this shortcoming of the method, the data in Table I do suggest that C.T. excretes relatively large 
amounts of sulfur as one or more unidentified compounds in the urine when she receives Lmethionine, whereas the control subjects do not. Thus, the excretion of unidentified neutral sulfur by the control subjects was no higher during the periods of L-methionine supplementation than during control periods, but C.T. excreted an additional 2 to 3 mmoles of unidentified neutral sulfur when she was given supplementary L-methionine.

To explore the chemical form of the excess urinary unidentified neutral sulfur excreted by C.T. after she received L-methionine, we measured the amount of urinary methionine present in bound form. Samples of urine were evaporated to dryness; $20 \mathrm{ml}$ of constant-boiling $\mathrm{HCl}$ was added for each $10 \mathrm{ml}$ of urine originally present; and the solution was heated at $110^{\circ} \mathrm{C}$ for 24 hours, evaporated to dryness, brought to $\mathrm{pH} 2.2$, and analyzed for its amino acid content. Methionine liberated by such acid hydrolysis represents bound methionine, and the amounts detected are listed in the last column of Table I. When J.R.McC. or T.H. received L-methionine, the urinary excretion of bound methionine did not rise in one case and rose only 0.14 mmole in the other. When C.T. received a smaller dose of L-methionine, her excretion of bound methionine rose approximately 0.5 mmole.

The urine collected during days 1,9 , and 23 of C.T.'s study (Figure 3) was analyzed for the $\alpha$-keto analogue of methionine, $\alpha$-keto- $\gamma$-methiobutyrate (26). No $\alpha$-keto- $\gamma$-methiobutyrate was found in the urine collected during day 1 (control period) and day 9 (period of L-cysteine administration), and 0.16 mmole was detected in the urine excreted on day 23. Thus, the $\alpha$-keto- $\gamma$-methiobutyrate does not account for a major portion of the unidentified neutral sulfur in the urine of C.T.

The amino acid chromatograms of the urine passed by C.T. during the period when L-methionine was administered revealed several as yet unidentified peaks that were not present in the chromatograms of the urine collected during any other periods.

\section{Discussion}

The nature of the enzymatic defect responsible for the clinical syndrome associated with homocystinuria appears to have been firmly established.
The direct evidence that cystathionine synthase activity is deficient $(12,13)$ has recently been supplemented by demonstrations $(14,15)$ that the concentration of cystathionine in brain tissue from homocystinuric patients is markedly lower than it is in brain tissue from control subjects. Many of the other enzymes involved in the metabolism of the sulfur amino acids [reactions 1 and 5, Figure $1(12,13,27)$ and reactions 7 and $9(14)]$ are unchanged in this condition. The evidence presented in this paper of the normal capacity of such patients to convert the sulfur of L-cysteine to inorganic sulfate suggests that cystathionine synthase deficiency is not accompanied by a significant alteration in the activity of the enzymes beyond reaction 5 .

Earlier studies (17-19) have established that the conversion of methionine to inorganic sulfate by mammals can occur via the sequence of reactions 1 to 6 , but the evidence that this is a major or obligatory pathway is less conclusive. Theoretically other known biochemical reactions can constitute alternative pathways, and the relative contributions of these possible pathways of methionine metabolism in normal man have not yet been fully assessed. The results of the present study indicate that patients whose deficiency of cystathionine synthase activity is such that they excrete abnormal amounts of homocystine in the urine have a reduced capacity to form inorganic sulfate from orally administered L-methionine: We interpret this finding as evidence that cystathionine synthesis is an obligatory reaction in the conversion of methionine to sulfate in man.

The finding also suggests that the deficiency of cystathionine synthase activity detected in the liver is associated with a generalized reduction in the body's capacity to convert homocysteine to cystathionine. Evidence from other studies $(27,28)$ indicates that two factors lead to this generalized reduction: $a$ ) the liver is the dominant site of cystathionine synthesis; and $b$ ) the enzyme defect is present in other tissues. Assays of rat and monkey tissues demonstrated cystathionine synthase activity to be present in the liver, brain; and pancreas (27). There was activity in rat kidney but not in monkey kidney. The relatively high concentration of cystathionine synthase activity in the liver and the size of this organ combine to make it the major site of mammalian cysta- 
thionine synthesis. Thus, an isolated hepatic defect would probably result in a marked reduction in the body's capacity to form cystathionine. However, post-mortem brain tissue from a patient with homocystinuria had a specific defect in cystathionine synthase (28), suggesting that the enzymatic defect first discovered in hepatic tissue also involves other organs.

The two patients with cystathionine synthase deficiency were able to convert some L-methionine to inorganic sulfate (Figures 3 to 5 ). This small degree of conversion could be due either to the presence in these patients of residual cystathionine synthase activity sufficient to achieve the observed conversion or to the existence of an alternative pathway for methionine metabolism. The data presented in Figure 5 establish that the normal subject can convert at least 0.85 mmole of methionine per $\mathrm{kg}$ per day to inorganic sulfate. Therefore, a patient with $12 \%$ of the mean control hepatic cystathionine synthase activity, such as M.A.G. (13), should be able to convert at least 0.1 mmole per $\mathrm{kg}$ per day. Thus, it seems reasonable to attribute the ability of the two patients to increase urinary excretion of inorganic sulfate after the administration of L-methionine to their residual cystathionine synthase activity.

The present studies reveal that patients with cystathionine synthase deficiency retain abnormal amounts of ingested methionine. During the studies described in Table I, C.T. excreted in the urine an average of only $20 \%$ of the sulfur contained in her L-methionine supplement, whereas T.H. and J.R.McC. excreted 58 and $90 \%$, respectively. Furthermore, she accumulated abnormal amounts of methionine and methionine sulfoxide in the plasma and continued to excrete large quantities of these two compounds in the urine for an abnormally long time after supplementary L-methionine had been discontinued. This evidence also suggests that during the period of L-methionine supplementation C.T. was in abnormally positive sulfur balance, although this conclusion can be confirmed only by complete balance determinations. The chemical form and the tissue in which methionine is stored and the cause of the prolonged retention must be explained.

Although attention has been focused.mainly on the urinary excretion of homocystine in cystathionine synthase deficiency, the data presented in
Table I indicate that homocystine is not necessarily the most abundant abnormal sulfur-containing compound in the urine. During day 23 of C.T.'s study she excreted 0.12 mmole of homocystine, 0.34 mmole of methionine, 0.48 mmole of methionine sulfoxide, 0.86 mmole of bound methionine, and 4.0 mmoles of unidentified neutral sulfur. Although the amounts of methionine and its sulfoxide were not significantly greater than the values observed in studies of control subjects, the amounts of bound methionine and unidentified neutral sulfur were distinctly abnormal. These values emphasize the extent to which the amount of unidentified neutral sulfur exceeds that of the sulfur in known amino acids. Attempts to determine the chemical nature of the unidentified neutral sulfur are now in progress.

\section{Summary}

1. Patients with homocystinuria due to cystathionine synthase deficiency have an impaired capacity to convert the sulfur of orally administered L-methionine, but not L-cysteine, to urinary inorganic sulfate. This observation suggests that cystathionine formation is an obligatory step in human catabolism of methionine to inorganic sulfate.

2. The patients were able to convert a small amount of L-methionine to inorganic sulfate. This limited catabolism may be due to their residual hepatic cystathionine synthase activity.

3. The urinary excretion of inorganic sulfate after the administration of a single dose of Lmethionine distinguished the homozygote for cystathionine synthase deficiency from control subjects. The responses of two heterozygous subjects were within the control range.

4. During the administration of L-methionine to a patient with cystathionine synthase deficiency the urinary excretion of homocystine did not increase markedly. Abnormal amounts of methionine and methionine sulfoxide accumulated in the plasma, and these compounds were excreted in large quantities in the urine for an abnormally long time after L-methionine supplementation had been discontinued.

5. Homocystine is not necessarily the most abundant abnormal sulfur-containing compound in the urine of these patients. During L-methionine supplementation excessive amounts of bound meth- 
ionine and of unidentified neutral sulfur were detected in the urine. Their quantities exceeded that of the homocystine.

\section{Acknowledgments}

We are grateful to Dr. William C. Alford for performing the analyses for the various forms of urinary sulfur during the early studies of C.T. and for helping us set up the assay methods in our laboratory. Mrs. Minnie L. Woodson and Mr. William A. Edwards provided technical assistance during the study. Miss Jeanne M. Reid calculated and supervised the preparation and feeding of the metabolic diets. Dr. Robert K. Ockner contributed greatly to the clinical management of many of the subjects. That the subjects were as cooperative as they were and their urine collections as acurate as they were is attributable to the diligence of the nursing staff of ward 9 West of the Clinical Center. Dr. George L. Spaeth referred C.T. and M.A.G. to us for study.

\section{References}

1. Carson, N. A. J., and D. W. Neill. Metabolic abnormalities detected in a survey of mentally backward individuals in Northern Ireland. Arch. Dis. Childh. 1962, 37, 505.

2. Gerritsen, T., J. G. Vaughn, and H. A. Waisman. The identification of homocystine in the urine. Biochem. biophys. Res. Commun. 1962, 9, 493.

3. Field, C. M. B., N. A. J. Carson, D. C. Cusworth, C. E. Dent, and D. W. Neill. Homocystinuria. A new disorder of metabolism (abstract). Tenth International Congress of Pædiatrics, Lisbon, 1962, p. 274 .

4. Carson, N. A. J., D. C. Cusworth, C. E. Dent, C. M. B. Field, D. W. Neill, and R. G. Westall. Homocystinuria: a new inborn error of metabolism associated with mental deficiency. Arch. Dis. Childh. 1963, 38, 425.

5. Komrower, G. M., and V. K. Wilson. Homocystinuria. Proc. roy. Soc. Med. 1963, 56, 996.

6. Gerritsen, T., and H. A. Waisman. Homocystinuria, an error in the metabolism of methionine. Pediatrics 1964, 33, 413.

7. Gibson, J. B., N. A. J. Carson, and D. W. Neill. Pathological findings in homocystinuria. J. clin. Path. 1964, 17, 427.

8. Carson, N. A. J., C. E. Dent, C. M. B. Field, and G. E. Gaull. Homocystinuria. Clinical and pathological review of ten cases. J. Pediat. 1965, 66, 565.

9. Hall, W. K., M. E. Coryell, J. G. Hollowell, Jr., and T. G. Thevaos. A metabolic study of homocystinuria. Fed. Proc. 1965, 24, 470.

10. McDonald, L., C. Bray, C. Field, F. Love, and B. Davies. Homocystinuria, thrombosis, and the blood-platelets. Lancet 1964, 1, 745.

11. International Union of Biochemistry. Report of the Committee on Enzymes. New York, Pergamon, 1961, p. 127.
12. Mudd, S. H., J. D. Finkelstein, F. Irreverre, and L. Laster. Homocystinuria: an enzymatic defect. Science 1964, 143, 1443.

13. Finkelstein, J. D., S. H. Mudd, F. Irreverre, and L. Laster. Homocystinuria due to cystathionine synthetase deficiency: the mode of inheritance. Science 1964, 146, 785.

14. Brenton, D. P., D. C. Cusworth, and G. E. Gaull. Homocystinuria. Biochemical studies of tissues including a comparison with cystathioninuria. Pediatrics $1965,35,50$.

15. Gerritsen, T., and H. A. Waisman. Homocystinuria : absence of cystathionine in the brain. Science 1964, $145,588$.

16. Mueller, J. H. A new sulfur-containing aminoacid isolated from the hydrolytic products of protein. II. Sulfur excretion after ingestion. J. biol. Chem. 1923, 58, 373.

17. Lemann, J., Jr., and A. S. Relman. The relation of sulfur metabolism to acid-base balance and electrolyte excretion: the effects of DL-methionine in normal man. J. clin. Invest. 1959, 38, 2215.

18. Meister, A. Biochemistry of the Amino Acids. New York, Academic Press, 1957, p. 307.

19. Young, L., and G. A. Maw. The Metabolism of Sulphur Compounds. London, Methuen, 1958, p. 59.

20. Brand, E., M. M. Harris, and S. Biloon. Cystinuria. The excretion of a cystine complex which decomposes in the urine with the liberation of free cystine. J. biol. Chem. 1930, 86, 315.

21. Spaeth, G. L., and G. W. Barber. Homocystinuria in a mentally retarded child and her normal cousin. Trans. Amer. Acad. Ophthal. Otolaryng. In press.

22. Orr, M. L., and B. K. Watt. Amino acid content of foods. U. S. Dept. of Agriculture Home Economics Research Report No. 4. Washington, D. C., U. S. Government Printing Office, -1957.

23. Stein, W. H., and S. Moore. The free amino acids of human blood plasma. J. biol. Chem. 1954, 211, 915.

24. Spackman, D. H., W. H. Stein, and S. Moore. Automatic recording apparatus for use in the chromatography of amino acids. Analyt. Chem. 1958, 30, 1190.

25. Hawk, P. B., B. L. Oser, and W. H. Summerson. Practical Physiological Chemistry, 13th ed. New York, Blakiston, 1954, p. 949.

26. Towers, G. H. N., J. F. Thompson, and F. C. Steward. The detection of the keto acids of plants. A procedure based on their conversion to amino acids. J. Amer. chem. Soc. 1954, 76, 2392.

27. Mudd, S. H., J. D. Finkelstein, F. Irreverre, and L. Laster. Transsulfuration in mammals: microassays and tissue distributions of three enzymes of the pathway. J. biol. Chem. In press.

28. Mudd, S. H., L. Laster, J. D. Finkelstein, and F. Irreverre. Studies on homocystinuria in Symposium on Amine Metabolism in Schizophrenia. Atlantic City, 1965. 